\title{
Relational Perception and 'the feel' for Tools in the Wooden Boat Workshop
}

\author{
Tom Martin \\ Core Faculty, MA in Critical Craft Studies \\ Warren Wilson College \\ United States \\ Email:MartinCommaTom@gmail.com
}

\section{Abstract}

This paper presents insights into the lived experience of maritime carpentry practices, based on six months of sensory-ethnographic fieldwork as a wooden boat builder's apprentice. In particular, the author explores the widely-reported experience of tools 'withdrawing' from consciousness as craftspeople master their use. Without contradicting these interpretations many of which are constructed by way of reference to ideas from Merleau-Ponty - the author suggests further theoretical resources to examine the perceptual experience of work after tools cease to be the main focus of the craftsperson's attention. Heidegger's idea of 'circumspection' is presented as a way to illuminate the relational nature of the subsequent mode of perception, in which the work as a whole fills the consciousness, rather than the individual instruments through which the work is achieved.

Keywords: perception, craft learning, sensory ethnography, boat building, Heidegger, MerleauPonty

\section{Introduction}

The Riverside ${ }^{1}$ workshop is a non-profit organization devoted to the restoration and preservation of historic wooden boats, particularly those designed and built on the American mid-Atlantic coast. Like other organizations of its kind, Riverside is operated by a mix of paid staff and volunteers, with many of the latter participating in the hope of eventually developing the skills necessary to enter the trade professionally. I joined the workshop as a volunteer apprentice for a different reason: I wanted to know how the expert boat builders experienced their work, since I had a hunch that their skill was based on perceiving tools and materials in ways that outsiders to the profession could not. Through participating in the workshop, I intended to learn to see and feel maritime carpentry equipment more like the expert boat builders did, or at least to gather enough descriptions of their perception to start to understand their everyday experience.

Over six months of fieldwork, I slowly started to 'get the feel' for the most basic instruments of wooden boat restoration, although I cannot claim an understanding of the craft beyond a very basic level. I am, however, much more capable as a woodworker now than I was in my first days in the workshop, where I awkwardly fumbled with the few tools I was allowed to use, puzzling over why they failed to produce the results they did in the hands of the seasoned 
experts. I would stare at the wood plane as it chattered across the work surface, trying to understand why it nicked and gouged the wood rather than gracefully shaving off the thin layers I wanted. The permanent staff, by contrast, seemed not to notice their tools at all while they worked, intently focused on the surface of the wood as the plane floated across it. 'You're not holding the plane', one of the boat builders would eventually tell me, trying to explain why his work seemed so natural, and mine so forced; 'the plane becomes part of you'. The expert boat builders were all adamant that the answer lay in learning to sense the work through the tools, perceiving it as one might with fingertips alone.

In this paper, I explore the experience of embodied tool use by focusing on a characterization repeated frequently within the workshop as well as in academic literature, that tools 'recede' from consciousness as they are incorporated into the sense of the body (e.g., O'Connor, 2007, p. 188). My fieldwork findings supported this description to an extent, but also indicated that the experience was more complex than tools simply withdrawing from attention. After close consideration, I have concluded that the emphasis on objects receding from consciousness overshadows the equally challenging problem of what arises in their place. By considering my findings in light of ideas from phenomenological philosophy, I will show here that Heidegger's description of the relational interdependence of meaningful objects helps to illuminate the question of what craftspeople perceive when their tools and materials fade from awareness. In addition to commonly-used conceptual resources from Merleau-Ponty around the 'bodily schema' (1945/2002, p. 55), I will introduce Heidegger's notion of 'circumspec tion' $(1927 / 1962$, p. 98) in this analysis to illustrate how work practices, rather than the individual pieces of equipment that define them, fill the attention of the expert boat builder.

\section{Literature on Perception and Embodied Craft Learning}

This paper contributes to a growing body of literature on embodied practice in the craft workshop, a research topic that has become increasingly popular over the past few decades. As this small field has expanded, first-person methods have slowly gained traction, providing deeper philosophical insight as researchers pay more attention to their own lived experience of craftwork. Early studies of craft learning, such as those Coy collects in his edited collection Apprenticeship (1989), had a more sociological take on learning, investigating the institutions and social structures that governed collective participation in craft practices. More recently, though, craft researchers' focus has shifted towards sensory-ethnographic accounts of perceptual experience, tracking the ways in which engagement with the material world develops though learning. Sensory ethnography allows for the expansion of traditional ethnographic methods by taking sensation and perception as central foci, capturing detailed portraits of embodied experience through first-hand experience or through conversations with participants that elicit rich sensory accounts (Pink, 2009).

These experiential studies of perception and embodied learning are highly varied, contributing new philosophical and methodological insights appealing to readers interested in the phenomenology of practice. Particularly notable examples include Goodwin's work on perception as a collective social phenomenon (1994, 1995); Grasseni's research on how skillful perception constitutes meaningful objects $(2004,2009)$; and Ingold's wide-ranging experiential accounts of human interactions with the material world $(2000,2011)$. In this paper, however, I wish to focus on one particular strand of research on embodied understanding, in which researchers engage with ideas from Merleau-Ponty to describe their experience of incorporating 
tools into their perceptual apparatus. Such research hinges on Merleau-Ponty's concept of the 'bodily schema' (1945/2002, p. 55), through which he explains that familiar objects can extend the perceptual reach of the physical body, as the walking stick does for the blind man:

The blind man's stick has ceased to be an object for him, and is no longer perceived for itself; its point has become an area of sensitivity, extending the scope and active radius of touch, and providing a parallel to sight. (Merleau-Ponty, 1945/2002, p. 166)

Two aspects of this incorporation of tools into the body schema are repeatedly cited in empirical research on craft learning: first, that expert users can feel through tools as they feel through parts of their body; and second, that tools disappear from attention during this incorporated use, much as the body itself ceases to be the object of attention during skilled work. Banlield and Burgess (2013) interview craftspeople about their experience of materials, recording accounts of implements 'becoming part of the artist' (p. 86), and both Papadimitriou (2008) and Standal (2011) explain that with proper experience, a wheelchair 'ceases to be an object' (Standal, 2011, p. 180) in the mind of its user, becoming instead an instrument through which to feel the external world. A particularly well-developed analysis of this perceptual experience appears in O'Connor's sensory-ethnographic research in the glassblowing studio, where she records her changing experience of tools and materials over four years of research. A key aspect of her learned perceptual ability was the experience of seeing through tools, such as her blowpipe revealing the sense of the ledge of the kiln rather than its own weight in the hand (2005, pp. 188189). Additionally, as O'Connor became accustomed to them, the tools 'receded' from her awareness (2007, p. 188), combining with her body to facilitate the work at hand.

Overall, these Merleau-Ponty inspired readings of perception in craft practice illuminate the flexible boundaries of the perceived human body, which draws physical implements into its apparatus for sense-making during skillful work. While these descriptions shed light on the craftsperson's lived experience of their practice, however, they share a conceptual language that raises questions for further exploration, particularly around the incorporation of tools into the body schema. In particular, I ask in this paper whether a conception of tools as discrete objects to incorporate into the sense of the body does full justice to the perceptual experience of the craftsperson, which I contend relays the relationships between equipment as much as the sense of the equipment itself. To make this point, I will integrate ideas from Heidegger's Being and Time into my analysis, as I explain in the following section.

\section{Theoretical Perspective}

While my fieldwork in the wooden boat workshop could be interpreted with descriptions of tools receding from awareness as I incorporated them into my body schema, my main point here is that such description conveys only a limited sense of this perceptual experience. Instead, I will focus on what remains as the tool withdraws from consciousness, arguing that what the craftsperson experiences is the relationship between body, tool, and material as they are combined in human practices, rather than the material alone as revealed by embodied tools. To do so, I will turn to Heidegger's work for insight into more fundamental features of human perception, many of which Merleau-Ponty overlooks in emphasizing the role of the body.

The main theoretical resource I will draw upon here is Heidegger's notion of 'circumspection', ${ }^{2}$ the mode of engaging with the social-material world in which objects appear in terms of their purposes, or 'subordinate themselves to the manifold assignments of the 'in- 
order-to" (Heidegger, 1927/1962, p. 98). Through circumspection, one sees, feels, hears, or otherwise perceives objects in ways that are defined by the meaningful interrelationships in which these objects exist, such as the hammer appearing in perception pre-reflectively as a hammer, rather than requiring deliberate consideration before it can be understood. Key to the concept of circumspection is the idea that the hammer cannot be perceived as such without a working understanding of nails, wood, and carpentry practices; these complementary objects and practical purposes define the hammer's very existence within the craftsperson's phenomenal world. While a mass of steel and wood would still exist regardless of how it is observed, its interpretation as a hammer is dependent on recognizing the entire network of meaning that constitutes it as such.

To an extent, however, Heidegger's famous hammer example obscures the full thrust of his claims about circumspective perception. By considering the hammer as a stand-alone entity, entirely separate from the carpenter who uses it, we risk reproducing the stark subject-object dichotomy that he attempts to undermine in Being and Time. Heidegger contends that 'if we posit an "I" or subject as that which is proximally given, we shall completely miss the phenomenal content of Dasein'3 (1927/1962, p. 72); if our exploration of understanding starts from a notion of human subject encountering the strictly human-external world, we will ultimately misrepresent the phenomenal character of lived experience. Instead, Heidegger asks us to consider understanding in terms of the practices in which it is apparent, such as the act of hammering, where the carpenter and tool reveal themselves as relational and interdependent. While immersed in the flow of practical work, it is our progress toward practical goals that is illuminated by the spotlight of our attention, with our sense of ourselves and our tools appearing only through their connection to the project at hand. The work not only defines our perception of the tools and materials in use, but also dissolves our sense of ourselves as distinct subjects, presenting to consciousness the processes through which self and world interact.

The Heideggerian idea of circumspective perception therefore holds significant potential for the analysis of embodied craft practice in that it fruitfully complicates the oft-reported experience of practical equipment receding from attention during skilled work. Starting with the Heideggerian premise that our most fundamental experience of the world reveals self and objects in relation, rather than individually, then descriptions of tools 'receding' from attention begin to seem incomplete as accounts of lived experience. An example of this under-specification is apparent in Merleau-Ponty's own writing about the experience of tool-mediated perception, again through his famous example of the blind man's walking stick: "In the exploration of things, the length of the stick does not enter expressly as a middle term: the blind man is rather aware of it through the position of objects than of the position of objects through it" $(1945 / 2002$, p. 166).

In the above quote from Phenomenology of Perception, Merleau-Ponty focuses on how the tools that mediate perception cease to register in consciousness during skillful use. Instead, he writes, the body encounters only the object revealed by the tool, much as if that object were encountered through sight or unmediated touch. While this insight helps to clarify the way in which tools cease to appear to the user as discrete entities during skilled practice, it does not yet fully specify the texture of the subsequent perceptual experience, in which the embodied self encounters the objects disclosed by the tool. In particular, Merleau-Ponty does not engage with the question of how the object perceived is understood as such in the first place, ${ }^{4}$ an ontological question addressed explicitly by Heidegger with implications for analyzing the lived experience of practical work. In returning to Heidegger's notion of the relationality of circumspective 
perception, I will argue that perception does not merely reveal the connection between body and object, but between the self and the endless interconnectivity of situated meanings through which objects are defined. Perception in skillful work is marked, I argue, by the totality of practical, context-dependent relationships between objects - unfolding through the practices in which those objects are used - filling the consciousness, rather than individual tools simply ceasing to appear to their users.

\section{On Phenomenology and Sensory Ethnography}

Given the subject and readership of this journal, a few notes are necessary to clarify the ways in which I conceive of this as 'phenomenological' research. In brief, my main sense of a connection to phenomenology stems from my use of concepts from Heidegger and MerleauPonty in analysis, prominent figures in mid- $20^{\text {th }}$-century phenomenological philosophy. I have not, however, attempted to employ Husserl's classic technique of 'bracketing' in my efforts to collect research data; instead, I have turned to the tradition of sensory ethnography for inspiration about how to record my embodied and emplaced perception of the social-material world (Pink, 2009). Strict adherents to contemporary phenomenological research frameworks, such as that put forward by Giorgi (2009), may contend that this research does not constitute phenomenology in the sense popularly used in the social sciences today, as it does not explicitly deal with 'reductions' or the disclosure of 'essences' (a contention explored at length in Finlay, 2009). My hope is that such readers will at least acknowledge the phenomenological tenor of this research insofar as, in the words of van Manen, it 'attempts to gain insightful descriptions of the way we experience the world pre-reflectively' (1990, p. 9). By putting ideas from phenomenological philosophy into conversation with real-world experiential research data, I intend to contribute to ongoing conversations about the nature of understanding and the ways in which it unfolds throughout human practices, topics I believe to be of interest to readers of this journal.

\section{Getting 'the feel' for Everyday Tools}

The boat workshop that I joined as a volunteer apprentice was housed within a museum devoted to the preservation of historic wooden vessels, as well as preserving the skills needed for their construction and upkeep. The city in which the museum was located had once been home to a busy commercial seaport and a lively wooden boat building community, back when maritime carpentry was a viable trade. In the century that followed, however, almost all of these workshops closed as mass-produced steel and fiberglass boats displaced anything made from wood. Now, the few wooden boats that have survived are maintained by museums or private collectors, relics of a bygone age of small-scale craft production. To be a contemporary maritime carpenter is therefore to be a historian as much as a craftsperson, cataloguing the forms and construction methods apparent in surviving vessels before they are ultimately dissolved by wood rot. Perhaps predictably, this work is not well-funded, so the workshop at the maritime museum relies on a large contingent of volunteers; it was through this volunteer path that I took up a position in the workshop, where I intended to discover what it was like to understand the tools and materials of the trade as the boat builders did.

In my earliest days in the workshop, I had some trouble gaining access to the work practices I was most curious to experience, since the senior boat builders were cautious about 
giving me projects where I could do any significant damage. Instead, I was usually assigned to sanding and scraping away old paint before the senior carpenters did the interesting work of shaping and rebuilding the wood beneath, jobs that required the complicated tools I had not yet been shown how to use. While frustrating, this initial introductory period still proved highly instructional. From my position at the sanding cart in the middle of the workshop, I could watch the work of the expert boat builders, memorizing the steps in common restoration practices. I also listened in on their conversations, picking up the names of the tools and materials they used and following the debates they had about proper technique and historical accuracy. What I could not initially experience, however, were the physical sensations that the tools produced in the hands of their operators, and the ways in which these sensations signaled important aspects of the work; sanding and scraping were such blunt procedures that after a few days, I had examined my perceptual experience of them from every angle I could imagine.

One senior boat builder named Lou seemed particularly aware of the pedagogical limitations of these early stages of the apprenticeship, and began feeding me more complicated work as I proved that I could handle it. One of these more complex projects was the construction of a set of 'cradles' for moving finished parts from the workshop back onto Hercules, the historic ship being restored on the pier. In this instance, the components being transported were the giant skylights that let sunlight into the captain's quarters, hulking boxes made of century-old teak (Figure 1, right) that I would never have been allowed to work on, given my relative inexperience. My job instead would be to fabricate simple sleds for transporting the skylights, an unimpressive project in itself, but one that would play a key role in the delicate process of moving the skylights onto the ship by crane, therefore entailing an exciting new level of responsibility. I was determined to do an excellent job, showing how much I had learned in the workshop in my time there and hopefully winning access to even more interesting work in the future.
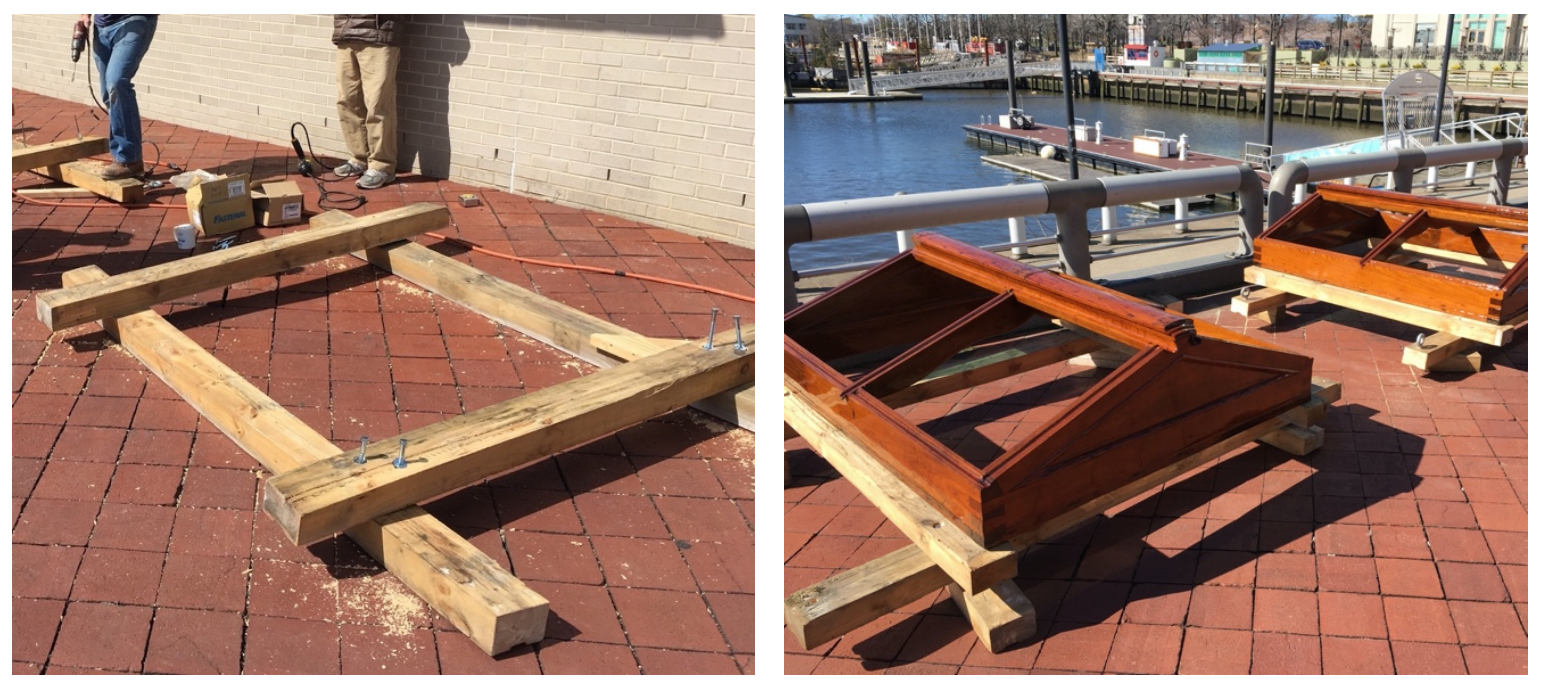

Figure 1: The cradles under construction (left), and the cradles in use (right)

The construction process for the cradles involved laying out four thick timbers to form a square with overlapping sides (see Figure 1, left) then screwing the timbers together where they met. My instructions were to drill a wide clear hole in the upper timber for the body of the screw 
to pass through, then a narrower pilot hole in the lower timber where its threads would engage the wood. This way, as the screw sank into the lower timber, it would pinch the two timbers together, forming a strong joint. I went straight to work drilling out holes and installing screws until Lou interrupted me, as I recorded in my fieldwork notes: ${ }^{5}$

when I got the head of the screw to the surface of the board, Lou stopped me, saying that the driver had so much torque it would actually shear the screw once the screw had sunk far enough. I commented that I didn't know if it was in far enough, because it hadn't pulled the lower timber up to connect with the upper timber yet; after all, the hole in the top timber was only a clear-hole. He replied that maybe I had some room to go yet, and that I'd 'get a feel for it' as I went.

The problem that Lou was pointing out was that I was attempting to determine whether the screws were tight enough by watching the gap between the upper and lower timbers disappear. The timbers were warped and twisted, though, so flattening them together would have required enough pressure to twist them straight, much more than was needed simply to secure them. The driver was capable of applying that much pressure, but the steel screws were likely to shear if I tightened them that much. The strategy Lou was suggesting was to determine whether the screws were tight enough by paying attention to how the driver felt in my hands, rather than by looking at the gap between the timbers, which was an unreliable indicator.

At first, I was skeptical of Lou's advice, since the driver exerted so much force that I struggled just to keep it in position, and the prospect of interpreting subtle differences in how it felt seemed unlikely. Bit by bit, though, it became apparent that the sense of the driver in my hand was not constant, but varied according to what obstacles the screw encountered. If the screw provided little resistance going into the wood, I would feel little resistance from the driver, whereas finishing the last few turns on a tight screw required me to put my back and upper arms into holding the driver in place. None of this meaning was apparent to me the first time I used the tool; while I must have been feeling the same things, I had yet to develop a meaningful framework in which to make sense of them. I puzzled over all of this while putting the cradles together, until Lou interrupted me again. 'Yep, you learned how to do that', he told me. 'That's all there is to it'. Apparently, my work signaled that I had started to get 'the feel' that he had wanted me to get.

\section{Relationships in Perceptual Understanding}

In 'getting the feel' for the driver at Riverside, I began to experience the tool through the mode of understanding that Heidegger refers to as 'circumspection', through which objects appear to the user in terms of the context-specific purposes to which they can be put (1927/1962, p. 98). The notion of circumspection folds perception and understanding into a single phenomenon, revealing associations between objects and their purposes in the act of seeing, rather than through deliberate consideration:

Whenever we see with this kind of [circumspective] sight, we already do so understandingly and interpretatively. In the mere encountering of something, it is understood in terms of a totality of involvements; and such seeing hides in itself the explicitness of the assignment-relations (of the 'in-order-to') which belong to that totality. (Heidegger, 1927/1962, p. 149) 
Heidegger mainly explains circumspection in terms of visual perception, but the idea applies to any sensory engagement with physical equipment that 'lets entities which are accessible to it be encountered unconcealedly in themselves' (1927/1962, p. 187). In learning to use the driver, I began to perceive it unconcealedly in itself, as a tool defined by the purposes for which it is used rather than an inert block of plastic and metal. At first, I only noticed the 'occurrent ${ }^{\text {' }}$ qualities of the driver, those relating to its 'bare physicality' (Heidegger, 1927/1962, p. 82) - its color, weight, and unpleasant vibrations, meaningless sensations that merely distracted from the work of watching the screw as it progressed. As I came to better understand the driver and the materials I was working with, though, the feeling of the driver in my hands started to convey a sense of meaning; I could feel the tension within the metal of the screws and the compression between the heavy timbers. I had begun to encounter the tool and materials circumspectively, where they arose in consciousness in terms of the practical purposes for which I was using them.

As soon as I learned to interpret the vibration of the drill in my hands, the sense it conveyed was that of the tension between the screw and the pine timbers, as driven by the electric tool: a relational nexus at which tool and materials met, rather than a single static object. While this kind of perception allowed me to experience several meaningful aspects of the work at hand at once, it also meant that any alteration to the constellation of tools and materials changed the experience entirely, as I quickly discovered. When the project changed, and with it the materials and practices with which I had associated the driver, I found that I could no longer interpret the sensations the tool produced. Since circumspection relies upon intimate familiarity with a situated network of practical meanings, shifting even a single node in that network disrupted my ability to fully understand the work at hand.

Once I felt I had mastered the high-torque driver, I made sure to demonstrate my newfound skill whenever possible, since I felt it marked me as someone capable enough to be trusted with more complicated equipment than the sanding block and paint scraper. An opportunity eventually arose for me to showcase my skills by drilling holes for new hardware on a set of enormous 'cat-heads', thick protrusions of solid wood that extend from the hull of a ship to hold the anchor aloft while at sea. The holes needed to be relatively large and perfectly straight, a combination that I recognized called for a 'Forstner' bit, the type more often used in a drill press (Figure 2). I grabbed a driver and got started, but quickly discovered that what I had learned previously did not translate well to this new job. The reason why, I eventually realized, was that the driver itself was just one variable in the equation, which also included the drill bit and the material being worked. In my previous project, the pine timbers and steel lag screws were both very soft, so my main concern was breaking one or the other. All I needed to develop a 'feel' for was the change in resistance the screw encountered as it sank, which was signaled by a slight increase in the pressure on my palm. 

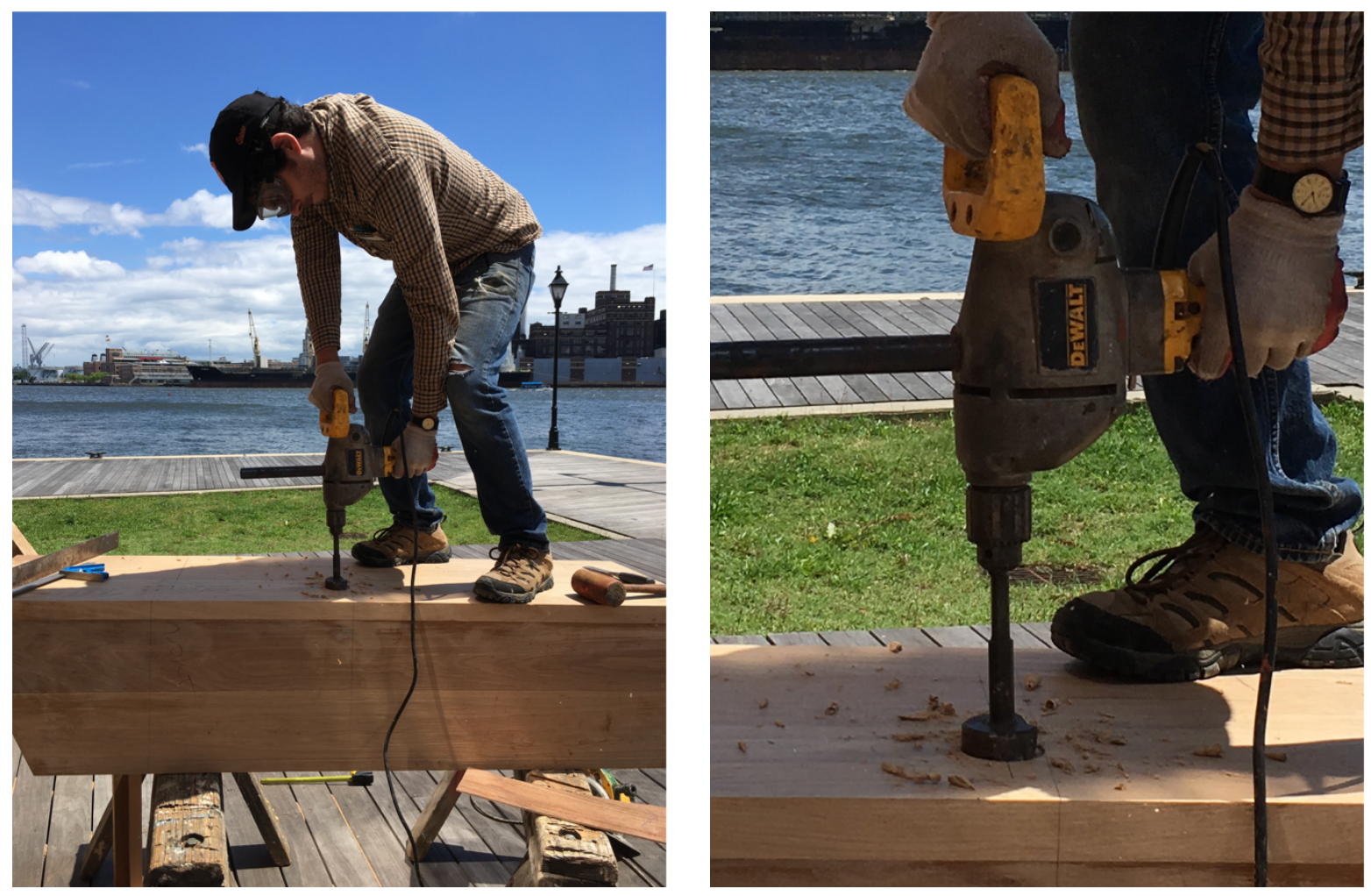

Figure 2: The author drilling holes in a cat-head (left); close-up of the tool with Forstner bit attached (right)

In this new project, however, the combination of the qualities of the white oak and the peculiar nature of the Forstner bit meant that I had to be aware of a very different set of possibilities. Since the oak was extremely hard, it pressed back against the drill bit, resisting its turning motion. If the force of this resistance overcame the force with which I was holding the driver, the driver itself would rotate rather than the bit, causing it to buck back against me and knock me off my feet. Normally this resistance would have been constant, and I could have prevented the tool from bucking just by learning how hard I needed to grip it. The design of the Forstner bit, however, meant that tipping the driver a few degrees in any direction increased the resistance it encountered significantly, so that if I accidentally changed the cutting angle at all, it would kick back violently. Getting 'the feel' therefore meant learning to differentiate between degrees of heavy resistance from the driver, determining when the force with which it pressed back indicated a clean cut, and when it meant that the bit was about to bind up and buck.

Even though the tool and materials in this task were superficially similar to those I had used previously, the slight differences in this new project shifted the relationships between driver and wood enough that my ability to encounter them circumspectively all but disappeared; only in discovering the possibilities and pitfalls that they presented in the new task would I be able to fully engage with them again. Despite their similarities - the drivers in the two instances were identical makes and models - these were essentially different tools, given the differences in the task-specific networks of meaning that defined them. In the new project, I had attempted to engage with the tool I was familiar with from my previous work, which I understood to be a 
conduit for transmitting force unidirectionally onto the materials. Kicking back against me when combined with a new bit and denser wood, however, the driver became a bidirectional conduit for twisting force, a very different tool and one which I initially failed to understand in any productive way. In light of Heidegger's notion of circumspection, it becomes apparent that such equipment essentially transforms as it is transferred between contexts, and can only be fully understood as a function the context-specific practices in which it is properly used, rather than as a stand-alone entity.

\section{Seeing the Work, not the Equipment}

So far, I have phrased my experiential account of my time in the workshop in terms of learning to see and feel objects circumspectively, with regard to their context-specific meanings. Some of the more complex examples, however, raise the question of whether this circumspective perception reveals the object per se, or if the sense of objects as discrete entities is overshadowed by a sense of their relationships to one another. For instance, in using the high-torque driver at Riverside, I learned to feel the tension on a screw as it pulled together pieces of pine. In one sense, I was feeling the driver in my hands, but in another I was feeling the combination of screw and wood that the sensation of the driver brought to mind.

This idea of perceiving the relationships between objects rather than the individual objects themselves was brought to my attention by my boat builder colleagues during our interviews before it occurred to me based on my own experience. In response to questions like 'What tools and materials is ['the feel'] particularly connected to?', boat builders sometimes produced specific examples - a particular hand tool, or a species of wood - but often pushed back on the question, explaining instead that their attention was filled with the work as a whole. Two long-time volunteers in the workshop, Mitch and Ray, provided one such response:

ME: Now, say something like this bandsaw; when you're using it, where's the focus of your attention? On the blade? On your hands? On the wood? ...

MITCH: I mean, I know where my hands are... but I'm focusing on where the material is, where the line is, relative to the blade. And more important, where it's going to be in the next couple seconds, what adjustments do I have to make in order to keep that exactly where I want it. ...

RAY: [Nodding] I think I'm more conscious of the work I'm working on, not the tool.

Mitch particularly draws out the relational nature of his perception in this excerpt, with the idea that his focus is on the point at which the blade and pencil line meet. This point is constantly in motion as the materials change in response to being worked, calling Mitch to attend to an unfolding process, rather than a static set of objects.

Heidegger points to a similar perceptual focus on work over equipment in explaining that the interconnectedness of equipment means that no individual piece of it is ever seen on its own through circumspective sight:

That with which our every-day dealings proximally dwell is not the tools themselves. On the contrary, that with which we concern ourselves is primarily the work - that which is 
to be produced at the time... The work bears with it that referential totality within which the equipment is encountered. (Heidegger, 1927/1962, p. 99)

Since the 'referential totality' of meaningful relationships is what determines how objects are perceived, it follows that to perceive an object circumspectively is primarily to perceive these relationships rather than a sense of it as independent from its context. And yet, a relational notion of perception is at first counter-intuitive, as it is not immediately obvious how a relationship is something that can be perceived. In my earlier examples, perception always presented a single physical object, even if that object was colored by the context in which it existed.

I found some guidance for the question of the experience of relational perception in considering another idea that came up repeatedly in my interviews, that familiarity with tools led to the sense that they faded into the body during use, as Lou described:

LOU: I like to say that you have to be part of the tool; it has to become you. You're not holding the plane; the plane becomes part of you. So a lot of times I watch people, and it seems like they're fumbling with this item, rather than that item being an extension of themselves, and I think that's where some of the skill comes in. You learn to use something... you learn and learn, and it becomes so second nature that you can pick it up and it becomes just part of you.

To an extent, I had expected this sort of description of experience in the workshop, based on having read Heidegger's account of equipment 'withdrawing' from attention once its user fully understands the context in which it exists (1927/1962, p. 99). To call Lou's description an example of 'withdrawal', however, would be to imply that his hand-plane simply ceased to be perceived, somehow retreating into an automatic process of which he was not aware. While the plane did cease to register in Lou's attention as its own discrete object, that was not because the plane had disappeared; rather, it was because the plane had become part of Lou's perceptual apparatus for encountering the material world circumspectively, in terms of the complex interrelationships that define how practical objects arise in consciousness. The relationality of this circumspective perception was particularly apparent while watching Lou use a large, unwieldy 'slick' chisel to remove a pocket of wood rot (Figure 3):

What Lou had to do was bring the rotten, uneven wood down to the level of the adjacent good piece. He placed the slick flat against the good piece and pushed forward, running it into the rotten piece and sending up curls of old wood.... I asked how Lou knew he was at the right depth, and he responded, 'I can feel it', pointing to the place where the bottom of the slick lay flat against the reference surface.

Mitch, who was also watching, seemed as impressed as I was, remarking to Lou that he 'could probably shave with that thing'. 'You could', Lou replied, humbly mistaking the compliment as a comment on the sharpness of the tool. 'You could', stressed Mitch, 'I couldn't. I'd probably slit my throat'.

Because Lou was very familiar with the use of the slick chisel, he was able to feel the surface of the wood he was working through the tool, rather than only perceiving the tool itself. MerleauPonty explains this kind of perception with his idea of 'bodily synthesis' (Merleau-Ponty, $1945 / 2002$, p. 176), in which one comes to understand tools as one normally understands the body, as a lens through which to perceive the world rather than as an object upon which the 
attention is focused. In light of this idea from Merleau-Ponty, the slick does not 'withdraw' so much as it becomes integrated into Lou's most fundamental way of understanding the world, that for which the body is the ultimate precedent. The idea of bodily synthesis therefore illuminates one aspect of the relationality of perception, that some objects present other objects to our attention rather than presenting themselves, much as the hands reveal the sensation of an object touched rather than the sense of their own weight and texture.

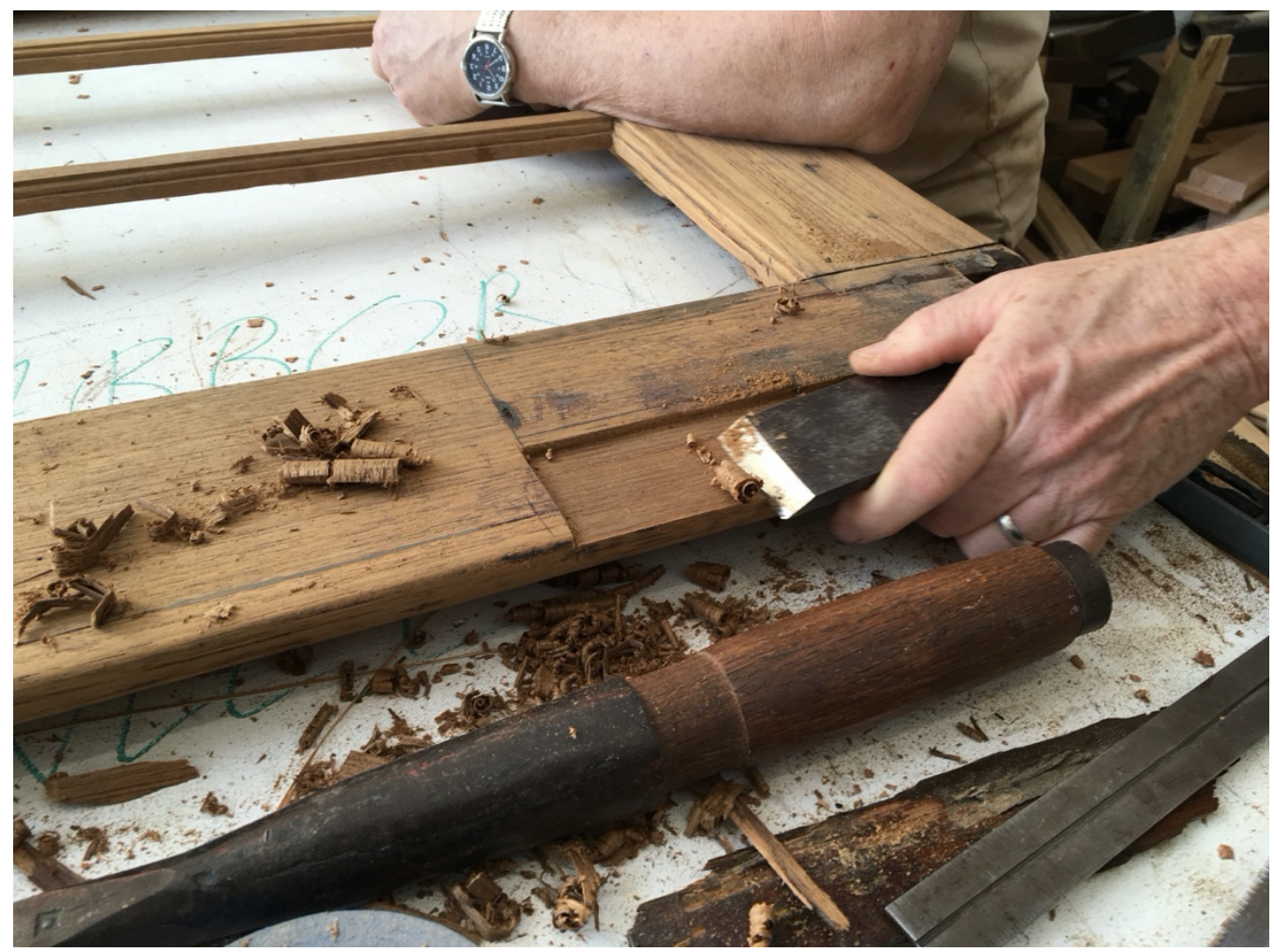

Figure 3: Lou at work with a large 'slick' chisel

Yet in using the slick to feel the level of wood he was shaping, Lou accomplished more than feeling through the tool to sense the material as he would with his hands; instead, he relied on the specific properties of the tool to examine aspects of the work that his hands could never reveal, features of the interface between tool and material rather than of the material alone. Since the bottom of the slick was a completely flat edge, Lou could feel where the uneven rot pocket he was removing finally gave way to the smooth surface produced by the slick, sensing the level of the wood by the way the tool sat on the work piece. An occurrent perspective, focused on the objects as discretely-bounded entities, would disclose these interfaces only in terms of the qualities of each individual object; a circumspective perspective, by contrast, subordinates the perception of tools and materials as discrete objects to an understanding of the progress of the practices in which they are used. Here, the quality of the work that signaled progress to Lou was flatness, which is presented by neither the wood nor the chisel alone. Instead, flatness is a function of how the chisel lies across the wood - where it rocks into a tiny crevice, or where it butts against a high spot indiscernible with the eye. Circumspective engagements bring these 
relationships to mind as features of the work underway, rather than as qualities of distinct objects.

When I was eventually allowed to do similar chiseling work, albeit with smaller chisels and less precious materials, I needed to regularly stop what I was doing to check the level of the wood with a ruler, looking for gaps between the ruler's edge and the work surface to find high spots I still needed to remove. I had not yet developed Lou's facility with the tool, through which to perceive the flatness of the surface as a function of the tool and material coming together. Instead, I was limited to a more occurrent perspective on the wood, which I understood to possess the quality of flatness on its own. Lou, by contrast, could sense the interface between the slick and the wood surface through the sensations that the tool produced in his hands, not only feeling through the tool, but circumspectively encountering aspects of the work that only this particular combination of tool and material could reveal. It was apparent in watching him that Lou's attention was fixed on the relationships between the tool, material, and his body, rather than any of these things on its own.

\section{A First-Person Perspective on Relational Perception}

In my early days in the workshop, I struggled to grasp the full relationality of circumspective tool use, and focused mainly on the feelings each tool produced in my hands. While I cannot say I mastered any particular tool over the course of my fieldwork, I did eventually begin to experience certain tools in more intimate ways, such as the thin-kerf handsaw I used to trim down wooden 'bungs'. This process involved fashioning tiny wooden plugs, setting them in place with wood glue, then sawing off the protruding ends once they had dried (Figure 4). While at first I managed to 'fumble' with the saw just adequately enough to get the work done, my attention was mostly devoted to the saw itself and the way I had to contort my body to use it, as I recorded in my fieldwork notes:

I found myself tensing my hand as I used it, trying to keep it steady while applying the necessary pressure to cut back and forth; as a result, my hand cramped up within minutes. ... When I wrapped my hand around the saw handle rather than pressing down on it with my pointer finger, it felt unwieldy and bound against the material constantly. ... I was only really able to keep it from binding (and therefore stopping mid-push) by tensing up my body and making little back-and-forth cuts, which I suspect is amateurish. 

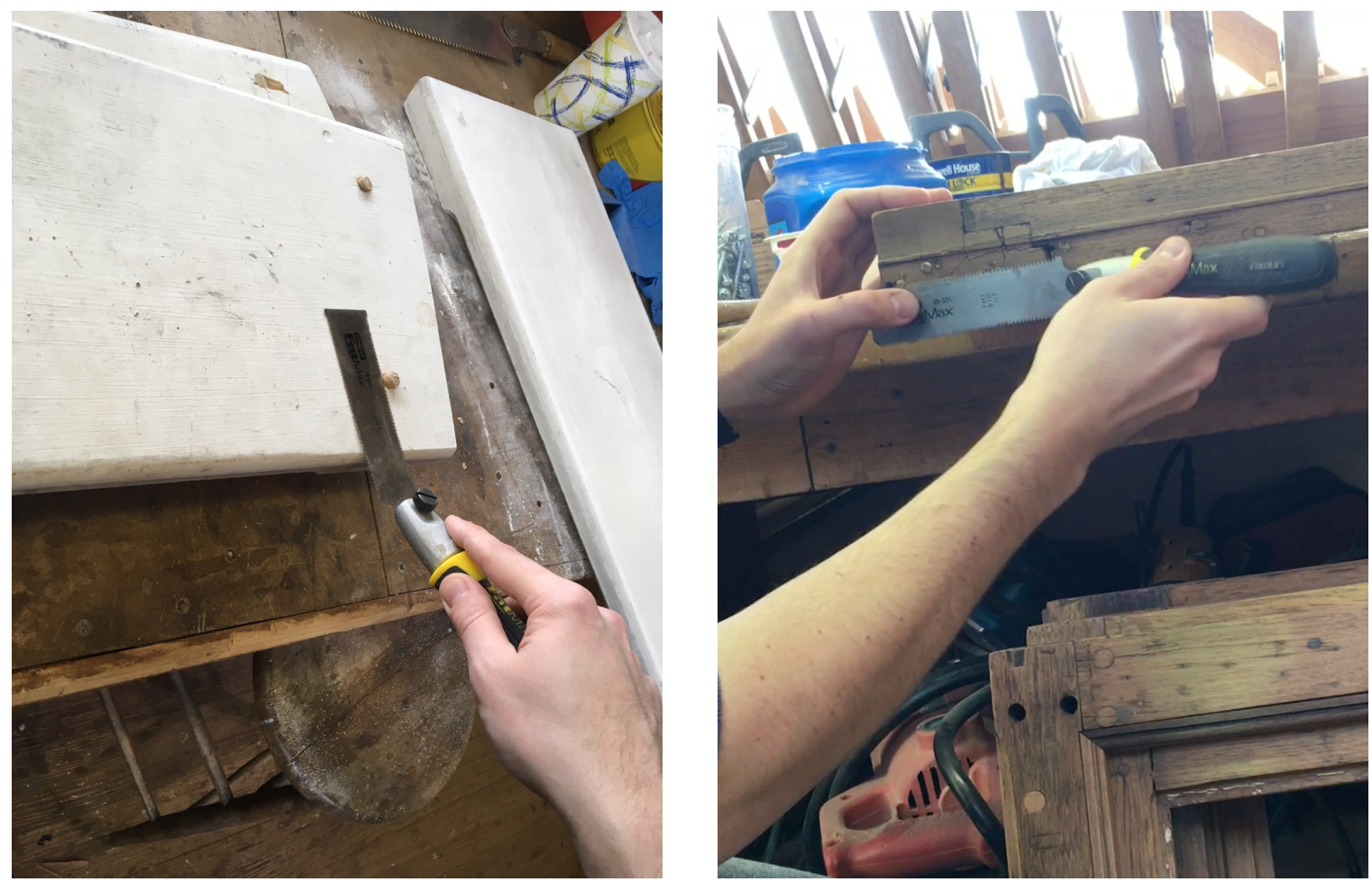

Figure 4: My original grip on the thin-kerf saw (left), and after becoming more comfortable with

\section{it (right)}

Struggling through these first few bungs, I focused almost entirely on the saw, trying to figure out why it kept binding against the wood. It jerked back and forth across the bung, giving no obvious indication of when it would get stuck, when it would glide through easily, and when the line it cut would change directions. I kept my hand rigid in an attempt to control the angle of the cut (Figure 4, left), but the tendons across its top quickly got sore from the constant tension, and I needed frequent breaks to let my hand relax. I managed the work, but the results were imprecise, and the pain in my hand lingered into the evening.

I carried on doing bunging work anytime it came up, though, and eventually my sense of the thin-kerf saw changed. Two weeks after first encountering it, I noted that it demanded less of my attention, allowing me to better focus on the process rather than just the tool:

I seem to have made enough progress with the zero-kerf saw that my grip on it, the feeling of it in my hand, and even my sense that it is there have largely disappeared. Instead, I watch just the cutting edge of it, seeing it not so much as a tool but rather as the advancing line being cut into the wood; it is the cut I am watching, not the blade. Occasionally it snags on some rough patch or bit of glue, pulling my attention back to it, but I find that when I have cleaned it recently (it gets filled with wood glue and then behaves poorly) it eases out of perception, leaving only the changing materials.

My photos from this day show a much softer grip on the saw, cradling it in my palm rather than choking it between two fingers (Figure 4, right). Meanwhile, my left hand had come into play as well, flattening the saw blade against the work surface to ensure a level cut. It is remarkable that 
I did not register the other hand in my notes, as my attention was entirely on the progressing cut. In the excerpt above, I remark that the saw had 'largely disappeared', but in light of ideas from Heidegger, a more precise interpretation is that I came to circumspectively experience the work that my hand, saw, and material produced in combination, rather than attending to each as its own discrete object. My sense of my body, the tool, and the material all collapsed into a single perception of the progressing cut, the work that defined each of its constituent components in this particular practice. I had started to understand these things in the way that would be most important for my work, in terms of the unfolding process that defined them.

\section{Discussion}

Although I began my research in the wooden boat workshop with a set of questions about how maritime carpenters experience their tools and materials, I eventually concluded that 'the feel' does not relate to any single object in isolation, but rather to the relationships between objects as they collectively fulfil a purpose. This relationality of perception follows from the Heideggerian premise that circumspection reveals objects as functions of the network of meaningful interrelationships in which they exist. Since fully understanding tools and materials demands recognizing an array of practice-oriented interrelationships, the experience of this equipment in use highlights these interrelationships rather than the discrete objects within them.

One particularly clear example of relational perception appears in my use of the hightorque driver. At first, the vibrations that the driver produced were meaningless to me, and I took them as excess sensory information that distracted from my work - a demonstration of what Heidegger calls an 'occurrent' stance toward objects. With time, however, I learned to judge the tension on the lag screw from the feeling of the driver in my hand, paying attention to differences in resistance and vibration, both of which signaled when the screw was close to snapping. In considering my later experience of the driver-screw combination, it is impossible to identify a single object of my perception in the way that I had in my early encounters with it, where I approached it from an occurrent perspective. Although I was interpreting meaning based on the sensory input from the tool itself, my increasingly circumspective perception related more clearly to the object manipulated by the tool; it was the screw, not the drill, with which I was concerned. Even the screw itself was not the sole object of my perception, however, since the tension I perceived existed between the screw and the wooden timbers that I was securing together. My perception was that of screw and wood interacting, as driven by a tool with particular capabilities, resulting in a relationship that I perceived as 'tightness'. The relationality of this circumspective perception was further indicated by my losing the ability to interpret the same tool when used in combination with other materials, which interacted in different ways. Once any one of the factors in the network of meaning changed, the range of possible perceptions changed as well.

To some extent, the relationality of circumspective perception was indicated in a description of experience cited by several of my participants, which the expert boat builder Lou explained as tools 'becoming part of you'. Such accounts of the incorporation of tools into the body point to the relationality of perception in that they stress the shift away from a sense of the tool as a discrete object, much in the same way that touching material with the hand does not convey a sense of the hand as a separate entity. As a consequence of this shift, Lou described being able to feel through the tool, experiencing the wood below it as he would with his own fingers. Similar descriptions appear in previous ethnographies of craft learning, including those by O'Connor (2007), who recounts that in becoming a proficient glass-blower, her tong-like 
'jacks' disappeared from her awareness. O'Connor writes, 'I was able to attend to the glass through the jacks to the extent that the jacks were no longer a conscious term of my action' (p. 72), stressing that the jacks appeared to her in the same way that her own body did, as a sensory apparatus with which to perceive objects outside herself. Like O'Connor and other sensoryethnographic craft researchers, I have drawn here from the work of Merleau-Ponty (1945/2002) to explain how tools extend the sensory capabilities of the human body, allowing for certain kinds of mediated perception and action that would not otherwise be possible.

While I agree to an extent with the description that familiar tools fade from awareness as bounded objects while in use, by using ideas from Heidegger, I have argued here that the materials being worked by the tools in hand cease to appear as singular entities as well, giving way to a sense of the process as a whole. Processes such as sawing and drilling are experienced circumspectively in the boat building workshop in terms of the progress of the practice toward its goal, rather than as the appearance or disappearance of the individual objects in use. A common example of this kind of relational perception, something I experienced myself as well as had reported to me by participants, occurred while using a hand saw to cut through wood. While the saw itself may have ceased to appear as a discrete object, giving the user the impression that it receded into the body, so too did the wood and the saw blade, which combined to produce the sense of the progressing cut. Each of the components in use in the process of cutting contributed an aspect to the perception of the practice, but none appeared in awareness as a single bounded entity, as if examined out of context. Therefore, where previous authors have focused on the disappearance of tools from awareness, I have stressed the disappearance of every discrete object, replaced with a circumspective sense of the progress of the work on the whole.

\section{Conclusion}

My goal in this paper is to contribute additional experiential texture to existing accounts of perception in the craft workshop, many of which rely upon the notion that tools 'recede' from consciousness as they are incorporated into the sense of the body (see O'Connor, 2007, p. 188). This interpretation is often based on ideas from Merleau-Ponty, particularly that of the flexible 'bodily schema' that adapts to incorporate external instruments as the user learns to use them to encounter the physical world (1945/2002, p. 55). Previous researchers have argued that craftspeople use their tools as a blind person uses a walking stick, as an implement through which to 'see' the surrounding environment by translating sensations in the hand into perceptions of the textures and spatial orientations of external objects.

While I do not disagree with the 'incorporation' thesis put forward by previous researchers, I have suggested here that it does not fully capture the lived experience of tool use, which is more complex than tools merely fading from conscious awareness. Instead, I have introduced Heidegger's idea of circumspection to show how the skillful perception of tools and materials entails understanding them in relational terms, rather than as discretely-bounded entities. The examples here show how the much-cited phenomenon of objects 'disappearing' or 'withdrawing' from consciousness captures the bodily synthesis that occurs by incorporating tools into the sense of the self, but poorly represents the relational perception that consequently takes their place. A better description, I argue, is that circumspection allows the wooden boat builder to perceive the interface at which tools and material meet, revealing an interaction between tool, materials, and the body rather than a sense of them as discrete entities. Combining ideas about bodily synthesis from Merleau-Ponty (1945/2002) with ideas about relational 
perception from Heidegger (1927/1962) has allowed me to move beyond descriptions of the sense of objects disappearing to exploration of the relational sense of object-interaction that appears in their place.

\section{Acknowledgements}

This paper is based on research conducted as part of a doctoral studentship supported by the UK Economic and Social Research Council (ESRC), award number ES/J500112/1. In accordance with ESRC 'Open Access' policy, the complete dissertation is available publicly through the Oxford University Research Archive (ORA), accessible at https://ora.ox.ac.u

\section{Endnotes}

${ }^{1}$ My participants and fieldwork sites have been anonymized throughout.

${ }^{2}$ While Macquarrie and Robinson present 'circumspection' as the translation for Heidegger's term umsicht, or 'looking around', this use does not carry the connotations of wariness or prudence that it does in English.

${ }^{3}$ The term 'Dasein' is much discussed in Heidegger scholarship, and is difficult to define concisely. In this instance, I understand Heidegger's use of the term to refer to a prototypical human being, particularly in regard to its specific capacity for engaging with the material world.

${ }^{4}$ In comparison to Heidegger, Merleau-Ponty is largely unconcerned with questions regarding the ontology of perceived objects. While a theory of object ontology may be implicit in his work (argues Dillon, 1988), I turn to Heidegger here for a more explicit ontological analysis.

${ }^{5}$ Because I was working alongside the boat builders during this research, my ability to take notes was somewhat hindered. My strategy for recording my thoughts and interactions with them involved quickly jotting down remarks in a pocket notepad, then unpacking these jottings in the evenings into long-form fieldwork notes as I reflected on what happened throughout the day. Consequently, only short snippets of conversation (e.g., the phrase 'get a feel for it' here) are repeated verbatim in my notes, as these could be transcribed easily in the moment. I later conducted long-form interviews with the boat builders as well, capturing their language and perspectives more precisely. ${ }^{6}$ Although Macquarrie and Robinson translate Heidegger's term vorhanden as 'present-at-hand', I substitute Wrathall's translation 'occurrent' (2013, p. 52), following his reasoning that this translation better captures Heidegger's intended meaning. 


\section{References}

Banlield, J., \& Burgess, M. (2013). A phenomenology of artistic doing: Flow as embodied knowing in 2D and 3D professional artists. Journal of Phenomenological Psychology, 44(1), 60-91.

Coy, M. (Ed.) (1989). Apprenticeship: From theory to method and back again. State University of New York Press.

Dillon, M. C. (1988). Merleau-Ponty’s ontology. Indiana University Press.

Finlay, L. (2009). Debating phenomenological research methods. Phenomenology \& Practice, $3(1), 6-25$.

Giorgi, A. (2009). The descriptive phenomenological method in psychology: A modified Husserlian approach. Duquesne University Press.

Goodwin, C. (1994). Professional vision. American Anthropologist, 96(3), 606-633.

Goodwin, C. (1995). Seeing in depth. Social Studies of Science, 25, 237-274.

Grasseni, C. (2004). Skilled vision. An apprenticeship in breeding aesthetics. Social Anthropology, 12, 41-55.

Grasseni, C. (2009). Developing skill, developing vision: Practices of locality at the foot of the Alps. Berghahn Books.

Heidegger, M. (1962). Being and time. (J. Macquarrie \& E. Robinson, Trans.). Blackwell. (Original work published 1927)

Ingold, T. (2000). The Perception of the Environment: Essays on livelihood, dwelling and skill. Routledge.

Ingold, T. (2011). Being alive: Essays on movement, knowledge and description. Routledge.

Merleau-Ponty, M. (2002). Phenomenology of perception (C. Smith, Trans.). Routledge \& Kegan Paul. (Original work published 1945)

O'Connor, E. (2005). Embodied knowledge: The experience of meaning and the struggle towards proficiency in glassblowing. Ethnography, 6(2), 183-204. 
O’Connor, E. (2007). Hot glass: The calorific imagination of practice in glassblowing. In C. J. Calhoun \& R. Sennett (Eds.), Practicing culture. (pp. 57-81). Routledge.

Papadimitriou, C. (2008). Becoming en-wheeled: The situated accomplishment of reembodiment as a wheelchair user after spinal cord injury. Disability \& Society, 23(7), 691-704.

Pink, S. (2009). Doing sensory ethnography. Sage.

Standal, Ø. (2011). Re-embodiment: Incorporation through embodied learning of wheelchair skills. Medicine, Health Care and Philosophy, 14(2), 177-184.

van Manen, M. (1990). Researching lived experience: Human science for an action sensitive pedagogy. Althouse.

Wrathall, M. (2013). Heidegger on human understanding. In M. Wrathall (Ed.), The Cambridge companion to Heidegger's Being and time. (pp. 177-200). Cambridge University Press. 